\title{
Influence of Ammonia Concentration on the Microstructure, Electrical and Raman Properties of low Temperature Chemical Bath Deposited ZnO Nanorods
}

\author{
Benard S. Mwankemwa ${ }^{1,2 *}$, Fred J. Nambala ${ }^{1,3}$, Farooq Kyeyune ${ }^{1}$, Thulani T. Hlatshwayo ${ }^{1}$, \\ Jackie M. Nel ${ }^{1}$, and Mmantsae Diale ${ }^{1}$ \\ 1. Department of Physics, University of Pretoria, Private bag X20, Hatfield, Republic of South Africa. \\ 2. Department of Physics, School of Physical Sciences, College of Natural and Mathematical Sciences, \\ University of Dodoma, P. O. Box 338, Dodoma, Tanzania. \\ 3. Department of Physics, University of Zambia, PO Box 32379, Great East Road Campus, Lusaka, Zambia. \\ *Corresponding author. E-mail address: benard_80@yahoo.com
}

\begin{abstract}
Nanostructured zinc oxide synthesized using an easy and low temperature chemical bath deposition method are among the most promising low cost semiconducting nanostructures investigated for a variety of applications. We successfully report the effects of ammonia solution in the growth of $\mathrm{ZnO}$ nanorods at a temperature of $60{ }^{\circ} \mathrm{C}$. Successive addition of ammonia altered the degree of supersaturation of the growth solution, causing a significant deviation in the morphology and crystal orientation of $\mathrm{ZnO}$ nanorods. Field emission scanning Electron Microscopy images revealed changes in surface morphology of $\mathrm{ZnO}$ nanorods with respect to addition of specific amounts of ammonia. X-ray diffraction analysis revealed wurtzite crystal structure of $\mathrm{ZnO}$ which was further further supported by $\mathrm{X}$-ray photoelectron studies, optical absorbance and Raman spectra that also revealed the existence of wurtzite $\mathrm{ZnO}$. The current-voltage measurement showed the electrical properties of the synthesized $\mathrm{ZnO}$ nanorods. The vertically grown nanorods with flat tops, effect more rectifying Schottky contacts to be realized on comparison to needle like structures.
\end{abstract}

Keywords: zinc oxide nanostructures; chemical bath deposition; growth mechanism, surface morphology, X-ray photoelectron spectroscopy, electrical properties 


\section{Introduction}

Zinc oxide $(\mathrm{ZnO})$ nanorods have attracted much interest as an $n$-type semiconductor with a wide direct band gap and a high excitonic binding energy of $3.37 \mathrm{eV}$ and $60 \mathrm{meV}$, respectively [1,2]. The material is very useful in many applications such as UV sensors [3], solar cells [4,5], light emitting diodes [6], piezoelectric [7] and spintronic devices [8]. In addition, $\mathrm{ZnO}$ nanorods are also used as photocatalysts, antimicrobial agents against food borne diseases and in food packaging [9-11]. For these applications, it is essential to gain a thorough understanding of the growth mechanism to achieve the desired size, shape and crystallinity. Wet chemistry methods have received much attention since they involve the use of simple experimental apparatus, low processing temperature and are environmentally friendly [12-14]. In particular, chemical bath deposition (CBD) is popular because it is a simple experimental setup, economical and can be used to deposit nanostructures on large, flexible and non-flexible substrates [15-17].

The growth of $\mathrm{ZnO}$ nanorods is due to the hydrolysis of zinc salts mixed with a basic compound, mostly hexamethylenetetramine (HMT) [18]. HMT is a non-ionic cyclic tertiary amine which hydrolyzes in water over a certain temperature range to produce formaldehyde ( $\mathrm{HCHO})$ and ammonia $\left(\mathrm{NH}_{3}\right)$. A $\mathrm{Zn}$ salt dissociates to produce $\mathrm{Zn}^{2+}$ ion, the only cation required for building up $\mathrm{ZnO}$ nanorods. The essential equations describing the $\mathrm{ZnO}$ nanorods growth under solution method are [19,20]:

$$
\begin{aligned}
& \left(\mathrm{CH}_{2}\right)_{6} \mathrm{~N}_{4}+6 \mathrm{H}_{2} \mathrm{O} \leftrightarrow 4 \mathrm{NH}_{3}+6 \mathrm{HCHO} \\
& \mathrm{NH}_{3}+\mathrm{H}_{2} \mathrm{O} \leftrightarrow \mathrm{NH}_{4}^{+}+\mathrm{OH}^{-}
\end{aligned}
$$

From the reaction (eqn. 2), $\mathrm{NH}_{3}$ produces hydroxyl $\left(\mathrm{OH}^{-}\right)$ions which react with $\mathrm{Zn}^{2+}$ produced by $\mathrm{Zn}\left(\mathrm{NO}_{3}\right)_{2}$, according to the following equations:

$$
\begin{aligned}
& \mathrm{Zn}^{2+}+2 \mathrm{OH}^{-} \leftrightarrow \mathrm{Zn}(\mathrm{OH})_{2} \\
& \mathrm{Zn}^{2+}+4 \mathrm{NH}_{3} \leftrightarrow\left[\mathrm{Zn}\left(\mathrm{NH}_{3}\right)_{4}\right]^{2+}
\end{aligned}
$$




$$
\mathrm{Zn}(\mathrm{OH})_{2} \rightarrow \mathrm{ZnO}+\mathrm{H}_{2} \mathrm{O}
$$

All these reactions occur under equilibrium and can be controlled by adjusting the growth parameters such as concentration of the reactants, temperature and $\mathrm{pH}$ by adding acidic or basic solution. This depends on the required $\mathrm{pH}$ value that will move the reaction equilibrium forward or backward. Apart from $\mathrm{Zn}(\mathrm{OH})_{2}$, there are other monomeric hydroxyl species such as $\mathrm{Zn}(\mathrm{OH})^{+}(\mathrm{aq}), \mathrm{Zn}(\mathrm{OH})_{3}{ }^{-}(\mathrm{aq})$ and $\mathrm{Zn}(\mathrm{OH})_{4}{ }^{2-}(\mathrm{aq})$ that are produced depending on the conditions. Richardson and Lange reported that the stability of these species depends on the $\mathrm{pH}$ and temperature of the growth solution [21]. Desai and Sartale [20] reported that there exists a competition between the species that form $\mathrm{ZnO}$ at lower basic concentrations where by both species can form but at higher basic concentration, $\mathrm{Zn}(\mathrm{OH})_{4}{ }^{2-}$ is the prevailing specie. Thus the $\mathrm{OH}^{-}$released from the decomposition of HTM is used to react with metal ion and form one of the monomeric hydroxyl species. Once all the $\mathrm{OH}^{-}$ions formed by decomposition of HTM have reacted with $\mathrm{Zn}^{2+}$ ions, the net reaction becomes:

$$
\left(\mathrm{CH}_{2}\right)_{6} \mathrm{~N}_{4}+8 \mathrm{H}_{2} \mathrm{O}+2 \mathrm{Zn}^{2+} \rightarrow 4 \mathrm{NH}_{4}^{+}+6 \mathrm{HCHO}+2 \mathrm{ZnO}
$$

However, adding ammonia solution drastically affects the growth of the nanorods as it alters $\mathrm{pH}$ and concentration of the growth solution. For lower concentrations of $\mathrm{NH}_{3}$, more $\mathrm{OH}^{-}$is produced (reaction 2). Addition of higher amounts of $\mathrm{NH}_{3}$ leads to the formation of amine complex (reaction 4) which lowers the degree of supersaturation of the growth mixture.

In this study, we have investigated the influence of ammonia solution as an external parameter on the growth of catalyst/surfactant free $\mathrm{ZnO}$ nanorods using low temperature CBD. The effect of ammonia was examined while keeping other growth parameters constant. We report that different morphologies of $\mathrm{ZnO}$ nanorods can be obtained at a low growth temperature by altering the amount of ammonia in the growth solution. 


\section{Experimental Procedures}

$\mathrm{ZnO}$ seed layers on $1 \mathrm{~cm} \times 1 \mathrm{~cm}$ indium doped tin oxide (ITO) substrates were prepared using spin coating method. Before deposition, substrates were thoroughly cleaned with detergent solution, rinsed with deionized (DI) water (Milli-Q, $18 \mathrm{M} \Omega . \mathrm{cm}$ ) followed by sonication in acetone, ethanol and finally DI water for 5 minutes each. The gel was prepared by dissolving zinc acetate dihydrate $\left(\mathrm{Zn}\left(\mathrm{CH}_{3} \mathrm{COO}\right)_{2} \cdot 2 \mathrm{H}_{2} \mathrm{O}\right.$, Merck) in ethanol to obtain a 35 $\mathrm{mM}$ solution and aged for $24 \mathrm{~h}$. The cleaned ITO substrates were spin-coated at $3000 \mathrm{rpm}$ for $1 \mathrm{~min}$ to form $\mathrm{ZnO}$ seed layer which was then dried in a pre-heated oven at $200{ }^{\circ} \mathrm{C}$ for $5 \mathrm{~min}$. The above procedure was done three times in order to increase the thickness of $\mathrm{ZnO}$ seed layer. Finally, the spin coated $\mathrm{ZnO}$ seed layer was annealed at $600{ }^{\circ} \mathrm{C}$ for $60 \mathrm{~min}$. The growth solution of the nanorods was prepared by dissolving equimolar amounts $(0.035 \mathrm{M})$ of zinc nitrate hexahydrate $\left(\mathrm{Zn}\left(\mathrm{NO}_{3}\right)_{2} .6 \mathrm{H}_{2} \mathrm{O} ; 98 \%\right.$, Sigma) and hexamethylenetetramine (HMT; 99.5 $\%$, Sigma) in DI water. The nanorods growth was accomplished by suspending substrates with seeded surface facing downwards (using non-releasable nylon cable ties) in the beaker containing the growth solution. The beaker was then placed in a water bath at a temperature of $60{ }^{\circ} \mathrm{C}$ for $4 \mathrm{~h}$. To investigate the influence of $25 \%$ ammonia solution, other experiments were carried out by adding $2-6 \mathrm{ml}$ of ammonia immediately as soon as the temperature of the growth solution reached $60{ }^{\circ} \mathrm{C}$ while keeping all other growth parameters constant. The temperature was then controlled and kept constant throughout the experiment. The schematic diagram in Fig. 1 shows a CBD method employed in this study for the synthesis of $\mathrm{ZnO}$ nanorods on a $\mathrm{ZnO}$ seeded substrate dipped into two different growth solutions. Finally, the substrates were removed from the growth beaker, washed with DI water and annealed at $400{ }^{\circ} \mathrm{C}$ for $30 \mathrm{~min}$. 


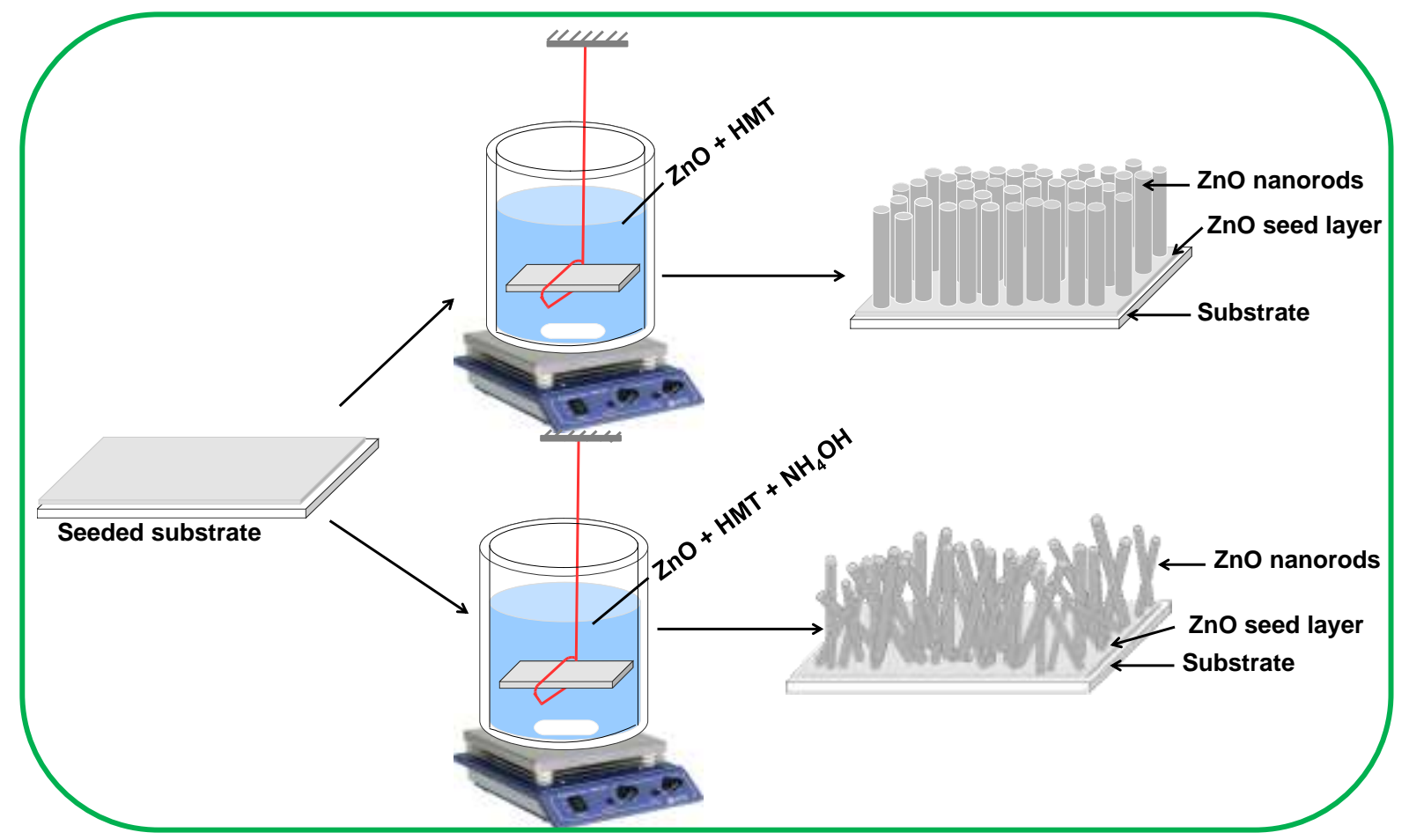

Fig. 1: Schematic diagram of the CBD technique for $\mathrm{ZnO}$ nanorods grown on seeded glass substrate.

The crystallographic properties and orientation of the nanorods were evaluated using Rugaku SmartLab X-ray Diffractometer with $\mathrm{Cu}-\mathrm{K} \alpha$ radiation $(\lambda=1.54056 \AA)$. The surface morphology of the nanorods were studied using field emission scanning electron microscopy (FE - SEM, ZEISS SEM-Microscopes Crossbeam|540). Elemental analysis of the nanorods was conducted using Thermo SCIENTIFIC K-Alpha Xray photoelectron spectrometer (XPS) using Al- $\mathrm{K}_{\alpha}$ radiation. Optical absorbance of the nanostructures was measured using a Varian Cary 100 UV-Vis Spectrophotometer. Raman studies were performed using Raman spectrometer Jobin Yvon, Horiba ${ }^{(\mathrm{C})}$ TX64000 using Arlaser emitting at $514 \mathrm{~nm}$. To investigate electrical properties of different morphologies obtained, Schottky diodes were fabricated. This was achieved by thermal evaporation of circular gold $\mathrm{Au}$ ) contacts using shadow mask placed on top of the substrate having $\mathrm{ZnO}$ nanorods as a top contact. ITO was used as ohmic contact as described in our previous work [22]. The current - voltage $(I-V)$ measurement of the fabricated Schottky diodes were measured at room temperature (RT) using SMU (Key sight B2912A) Keithley 230 meter. 


\section{Results and Discussion}

Since it is very important to have comparable results prepared under the same conditions, we used seed layers with similar structural and morphological properties throughout the experiment. Fig. 2 (a) shows XRD structural pattern of $\mathrm{ZnO}$ seed layer used with sharp peaks indicating high crystalline nature of the deposited seed layer. Further, Fig. 2 (b) presents its corresponding FESEM image of the seed layer. The $\mathrm{ZnO}$ seed layer is comprised of small densely packed grains with reduced porosity indicating good crystallinity of the film and thus favourable surface for the growth of the nanorods.
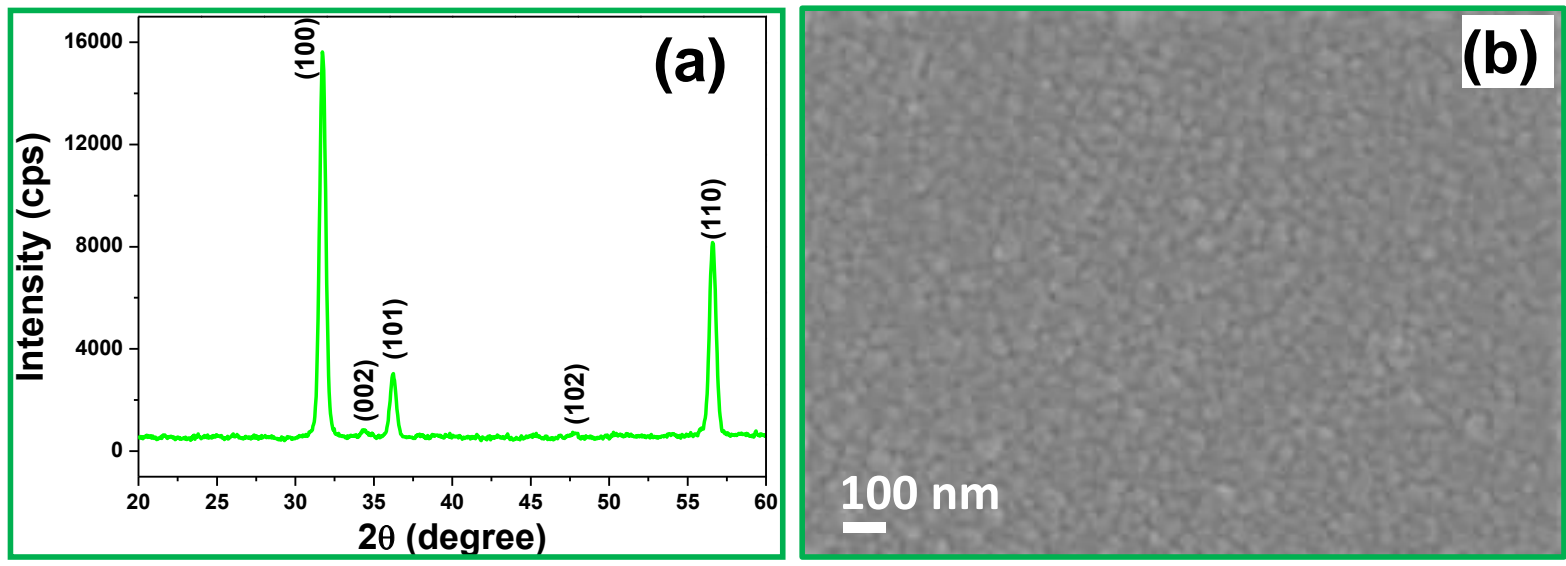

Fig. 2. (a) XRD pattern of the seed layer annealed at $600{ }^{\circ} \mathrm{C}$ and (b) its corresponding FESEM image.

Fig. 3 shows FESEM images of (a) $\mathrm{ZnO}$ nanorods without ammonia (reference sample) and (b) - (d) $\mathrm{ZnO}$ nanorods obtained after adding ammonia concentration on the growth solution. All samples display the hexagonal-shaped $\mathrm{ZnO}$ nanorods grown on the seeded ITO substrate with clean surfaces indicating the absence of notable impurities. For the reference sample shown in Fig. 3 (a), a dense array of nanorods is obtained with diameter ranging from 60 to $90 \mathrm{~nm}$. From this reference result, we found that the concentration as well as temperature of the growth solution was appropriate for the growth of flat tops, hexagonal shaped $\mathrm{ZnO}$ nanorods. It is clear that the diameter and density of the nanorods gradually decreased when $2 \mathrm{ml}$ (Fig. $3 \mathrm{~b}$ ) and $4 \mathrm{ml}$ (Fig. $3 \mathrm{c}$ ) of ammonia solution were added in the growth solution, respectively. This reveals that the concentration of the growth solution were altered upon 
addition of ammonia and thus caused a decrease in the growth rate. Similar consequences were reported by Chen et al [23]. They indicated that the increase in ammonia resulted in the decrease in the nanorods diameter.

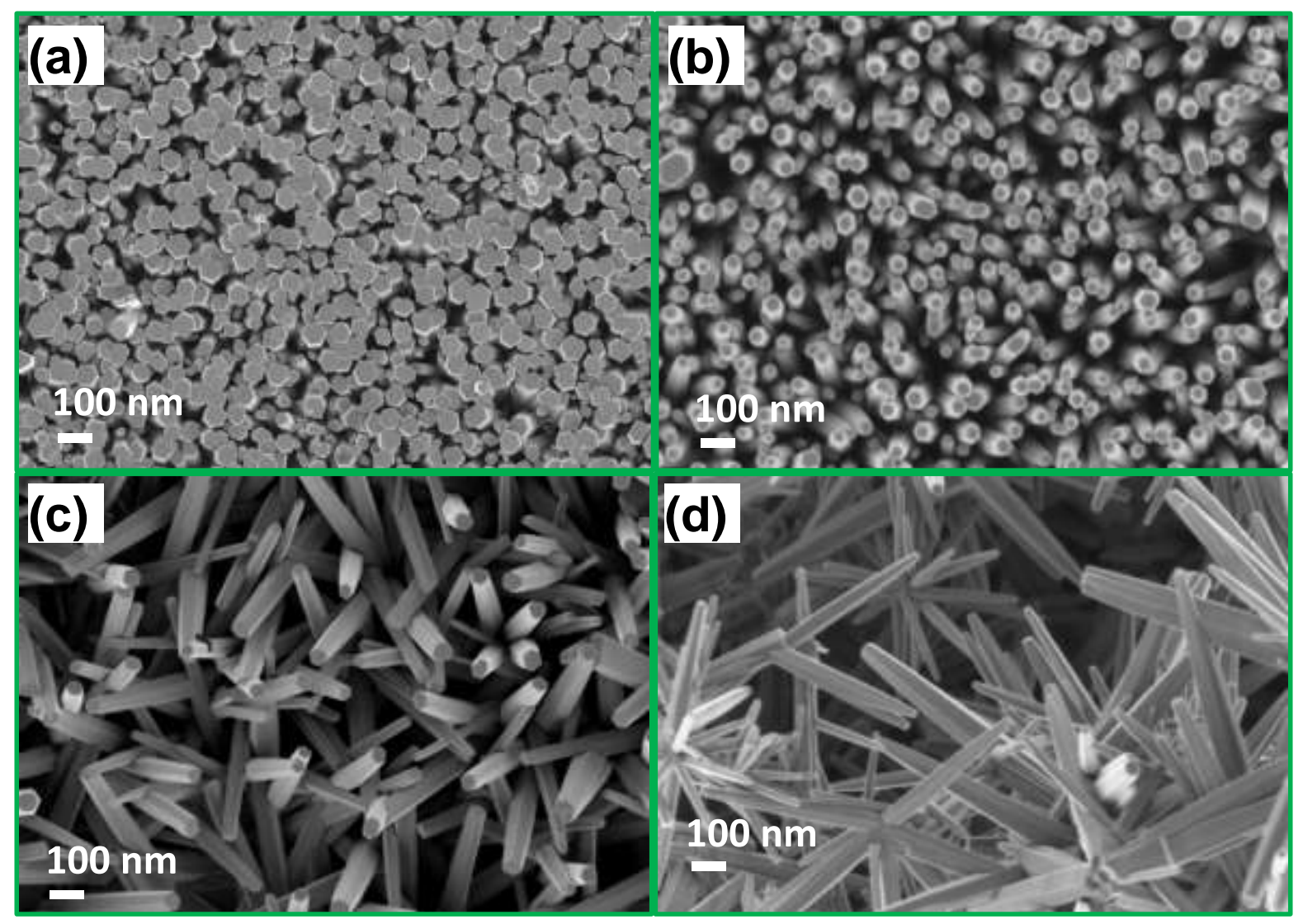

Fig. 3. (a) $\mathrm{ZnO}$ nanorods without $\mathrm{NH}_{3}$ solution (reference sample), (b) $2 \mathrm{ml}$, (c) $4 \mathrm{ml}$ and (d) $6 \mathrm{ml}$ of $25 \% \mathrm{NH}_{3}$ solution.

On further addition of ammonia to $6 \mathrm{ml}$ (Fig. $3 \mathrm{~d}$ ), a remarkable change in the morphology was observed where structures consisting of tapered needles originating from a common point were found randomly dispersed on the substrate. This growth may be due to the excess $\mathrm{OH}^{-}$from the decomposition of ammonia in agreement with published results [24,25]. Furthermore, the decrease in diameter and change of orientation of $\mathrm{ZnO}$ nanorods is due to the large amount of $\mathrm{OH}^{-}$that is produced as reported elsewhere [26]. This might cause $\mathrm{Zn}^{2+}$ to precipitate quickly and eventually results in the fast consumption of the nutrient thus prohibiting the oriented growth of the nanorods [18]. Kwon et al [27] reported that further 
addition of ammonia solution induces the formation of amine complexes as shown in equation (4) which precipitates in the solution. When this precipitation exceeds the number of nuclei, mult-angular orientated building blocks will grow on seeded substrates. Additionally, it can be seen in Fig 3 (d) that some of the multidirectional units do not all originate on the seeded substrate. This could be attributed to the high degree of supersaturation of the growth solution resulting in heterogeneous growth as it was reported by Desai and Sartale [20] that homogeneous and heterogeneous growth are favoured under low and high degree of supersaturations, respectively.

Fig. 4 shows in-plane XRD patterns of $\mathrm{ZnO}$ nanorods prepared under different ammonia concentrations. All the peaks corresponds to the crystalline hexagonal wurtzite structure of $\mathrm{ZnO}$ (JCPDS, 36-1451), and no impurity phases from metallic $\mathrm{Zn}$ or from other $\mathrm{Zn}$ compounds were observed. The results demonstrates similar XRD patterns with differences in their relative intensities which could be due to their dissimilarities orrientation. The clear, sharp difraction peaks obtained indicates that the nanorods possessed excellent crystal quality, suggesting that the temperature used was preferred for thermal decompostion of the nutrients in the growth solution. Decreased peak intensities of $\mathrm{ZnO}$ nanorods along the (002) plane with addition of ammonia solution are clearly observed and agrees well with the orrientation of the nanorods presented in SEM images (Fig. 3). The nanorods of Fig. 3 a and b grown perpendicular to the subtrate, less in Fig. $3 \mathrm{c}$ and randomly grown in Fig 3 c. This might be due to disorder in the crystal stucture and the variation in morphological arrangement of the nanorods as the amount of ammonia increases. 


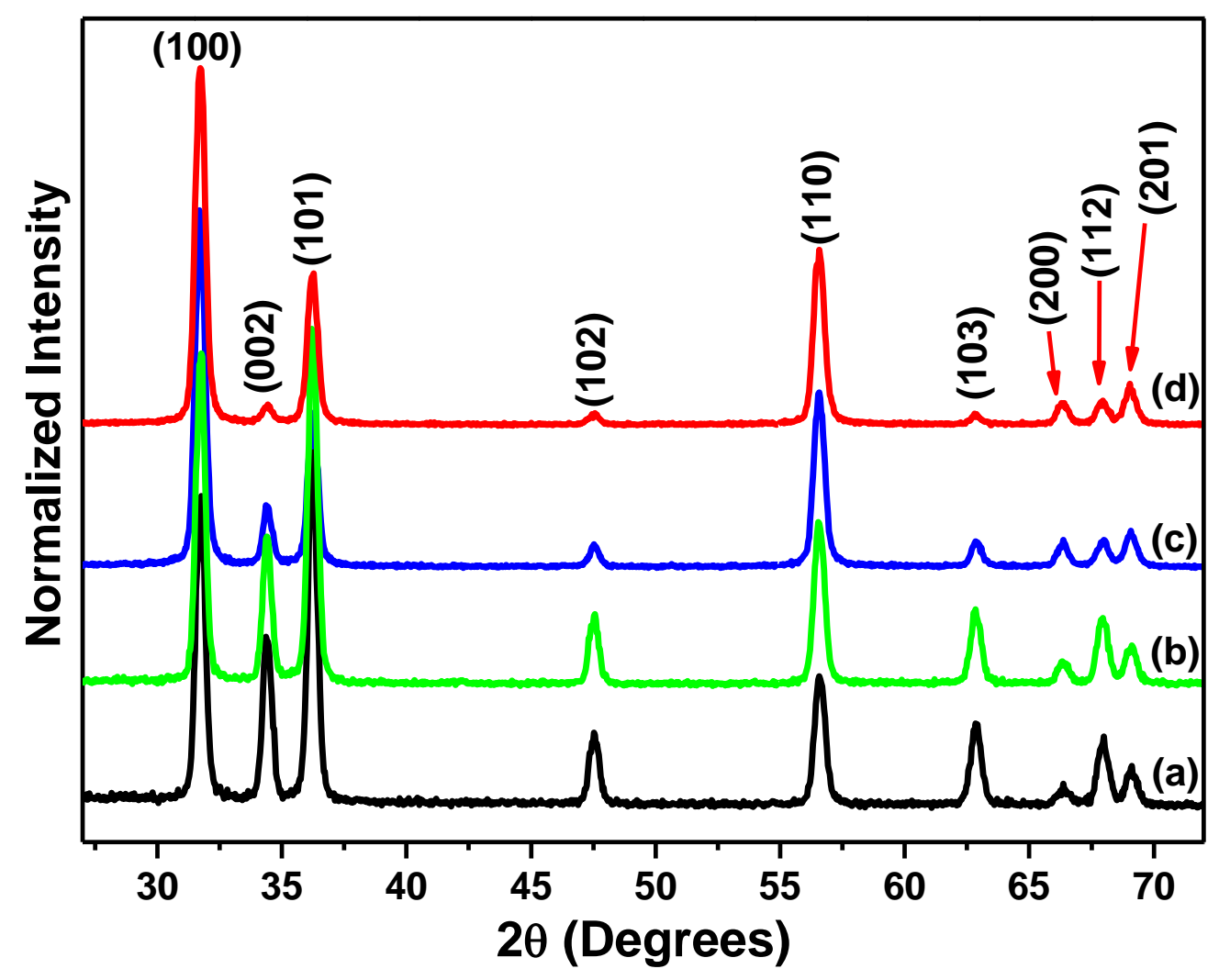

Fig. 4: X-ray diffraction patterns of $\mathrm{ZnO}$ nanorods: (a) reference sample (without $\mathrm{NH}_{3}$ ), (b) $2 \mathrm{ml}$, (c) $4 \mathrm{ml}$ and (d) $6 \mathrm{ml}$ of $25 \% \mathrm{NH}_{3}$ solution.

From the width of the XRD peak broadening, the crystallite size $(D)$ was calculated using Scherer's equation (7) [28] so as to explore further the effects of ammonia concentration on the crystal structure of nanorods.

$$
D=\frac{0.9 \lambda}{\beta \cos \theta}
$$

where $\lambda$ is the wavelength of X-ray radiation, $\theta$ is the Bragg's angle and $\beta$ is the full width at half maximum (FWHM) of the prominent peak. The crystallite size was calculated along the (100) peak and summarized in Table 1. The calculated crystallite sizes were observed to decrease with increasing concentration of ammonia in the growth solution. This also indicates an increase in the $\beta$ of the peak and thus a decrease in crystallinity of the obtained nanorods. This suggests that the concentration of $\mathrm{NH}_{4}{ }^{+}$and $\mathrm{OH}^{-}$in the growth solution plays crucial role in the formation of crystals and the crystalline quality in general. The results agree well 
with the XRD patterns shown in Fig. 4. The induced strain, $\varepsilon$, in the nanorods was calculated using the equation of Williamson and Hall [29].

$$
\beta_{h k l}=\frac{0.9 \lambda}{D \cos \theta}+4 \varepsilon \tan \theta
$$

where $\varepsilon$ is the induced strain and other symbols carry their usual meaning as defined above. It can be observed that an increase in ammonium concentration results in an increase in the strain, suggesting that the film experiences compressive strain. The lattice parameters, $a$ and $c$ of the $\mathrm{ZnO}$ wurtzite structure were calculated using equations below, respectively.

$$
\begin{aligned}
& a=\sqrt{\frac{1}{3}} \frac{\lambda}{\sin \theta} \\
& c=\frac{\lambda}{\sin \theta}
\end{aligned}
$$

The calculated lattice parameters tabulated in Table 1 were found to vary from one plane to another of the same sample and slightly higher than the standard lattice parameters of the bulk $\mathrm{ZnO}$ which are $a=3.2498$ and $c=5.2066 \AA$ A. This may be due to the increased concentration of ammonia in the growth solution which was observed to control the precipitation which resulted in changing atomic environment of the nanorods. Nelson and Riley equation 11 were used to correct the laticce parameter $a$ using four planes which are (100), (002), (101) and (110).

$$
F(\theta)=\frac{1}{2}\left(\frac{\cos ^{2} \theta}{\sin \theta}+\frac{\cos ^{2}}{\theta}\right)
$$

The intercepts of Nelson-Riley plots $\left(\theta=90^{\circ}\right)$, gives the corrected lattice parameter $a$ of each individual sample. The corrected lattice parameters obtained from equation 11 are shown in Table 1. We notice that the corrected lattice parameter, $a$, increased with increasing ammonia concentration indicating an increased volume of the cell. This confirms that 
ammonia concentration not only affects the morphology but also influences the volume of the cell.

Table 1. Lattice parameters, crystallite size, strain and dislocation density of the synthesized nanorods.

\begin{tabular}{ccccccc}
\hline \multirow{2}{2}{$\begin{array}{c}25 \% \text { of } \mathrm{NH}_{3} \\
(\mathrm{ml}) \text { solution }\end{array}$} & $a$ & $c$ & Corrected $a$ & $\begin{array}{c}\text { Crystallite } \\
\text { size } D(\mathrm{~nm})\end{array}$ & $\begin{array}{c}\text { Strain }(\varepsilon) \times \\
10^{-3}\end{array}$ & $\begin{array}{c}\text { Dislocation } \\
\text { density }(\delta) \\
\times 10^{4} \mathrm{~nm}^{-2}\end{array}$ \\
\cline { 2 - 6 } & 3.2526 & 5.2336 & 3.2315 & 19.86 & 6.7 & 2.54 \\
$\begin{array}{c}\text { Reference } \\
\text { sample }\end{array}$ & 3.2528 & 5.2341 & 3.2318 & 19.34 & 6.8 & 2.67 \\
2 & 3.2543 & 5.2367 & 3.2320 & 18.71 & 7.1 & 2.87 \\
6 & 3.2509 & 5.2308 & 3.2321 & 18.58 & 7.1 & 2.9 \\
\hline
\end{tabular}

The quantitative measure of defects in the synthesized nanorods, dislocation density $(\delta)$ along (100) preferred orientation of $\mathrm{ZnO}$ nanorods has been calculated using equation (12) and the results are as shown in Table 1.

$$
\delta=\frac{1}{D^{2}}
$$

where $D$ is the crystallite size. As shown in Fig. 5, dislocation density $(\delta)$ increases with increase in the concentration of ammonia indicating increased crystallographic defect or irregularity within crystal structure thus decreases the crystal quality of the obtained nanorods. To study the general variation of the bond length in the unit cell, equation 13 has been used [30].

$$
L=\sqrt{\left(\frac{a^{2}}{3}+\left(\frac{1}{2}-u\right)^{2} c^{2}\right)}
$$

where $u$ is the positional parameter in the wurtzite structure which is given by the following expression: $u=\frac{a^{2}}{3 c^{2}}+0.25$. The obtained $\mathrm{Zn}-\mathrm{O}$ bond lengths are $2.0344 \AA, 2.0345 \AA$, $2.0355 \AA$ and $2.0351 \AA$ for reference sample (without $\mathrm{NH}_{3}$ ), $2 \mathrm{ml}, 4 \mathrm{ml}$ and $6 \mathrm{ml}$ of $\mathrm{NH}_{3}$, respectively. The calculated bond length slightly exceeds $\mathrm{Zn}-\mathrm{O}$ bond length in the unit cell which is $1.9767 \AA$ [30]. However, the difference is very small indicating that the presence of 
ammonia had little effect on the expansion of the anion-cation bond length rather it changes the morphological shape of the nanorods as seen in FESEM images Fig. 3 (c) - (d).

The elemental compositions on the surface of $\mathrm{ZnO}$ nanorods were analysed using XPS. The wide (survey) scans of all the samples in Fig. 5 confirm the presence of elements $\mathrm{Zn}, \mathrm{O}$ and C. The observed $\mathrm{C}$ is mainly due to adventitious carbons absorbed on the surface during preparation (it should be noted that the samples were stored in ambient air). Thus, the obtained result confirmed the high purity of the $\mathrm{ZnO}$ nanorods and is in accordance with the XRD analysis.

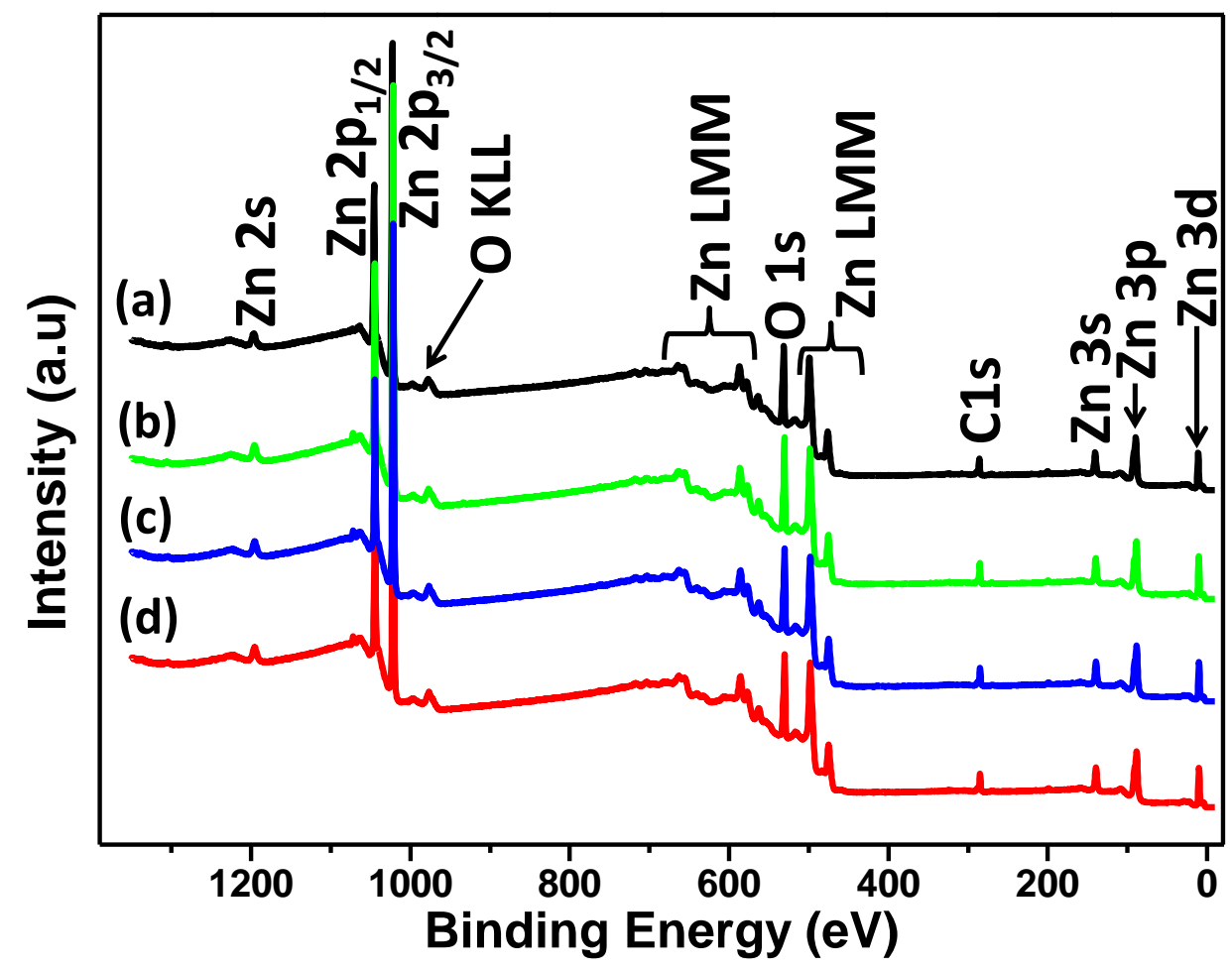

Fig. 5. XPS wide (survey) scans of $\mathrm{ZnO}$ nanorods (a) Reference sample (b) $2 \mathrm{ml} \mathrm{NH}_{3}$, (c) $4 \mathrm{ml} \mathrm{NH}_{3}$ and (d) $6 \mathrm{ml}$ of $\mathrm{NH}_{3}$ solution. 


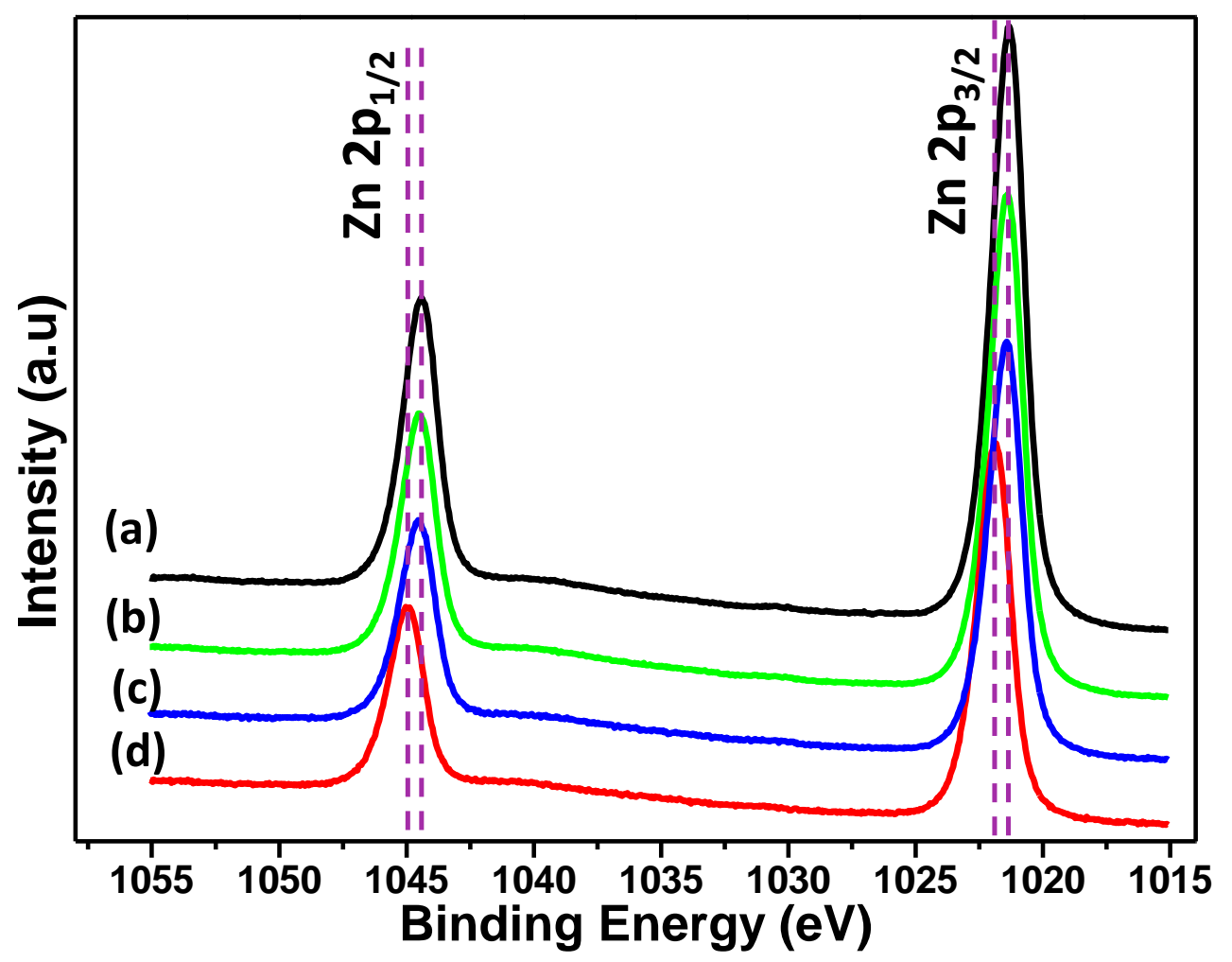

Fig. 6. High resolution XPS spectra of $\mathrm{Zn} 2 \mathrm{p}$ of $\mathrm{ZnO}$ nanorods (a) Reference sample (b) $2 \mathrm{ml} \mathrm{NH}_{3}$, (c) $4 \mathrm{ml} \mathrm{NH}_{3}$ and (d) $6 \mathrm{ml}$ of $\mathrm{NH}_{3}$ solution.

Fig. 6 shows high resolution spectra of $\mathrm{Zn} 2 \mathrm{p}$ acquired using the same photon source as the survey on the same page. The shape of the $\mathrm{Zn} 2 \mathrm{p}$ doublet peaks do not change with ammonia apart from a slight shift observed upon addition of $6 \mathrm{ml} \mathrm{NH}_{3}$ solution. For the first three samples (reference sample, $2 \mathrm{ml} \mathrm{NH}_{3}$ and $4 \mathrm{ml} \mathrm{NH}_{3}$ solution), the doublets corresponding to the $2 \mathrm{p}_{3 / 2}$ and $2 \mathrm{p}_{1 / 2}$ photoelectron core level peaks are positioned at $1021.29 \mathrm{eV}$ and 1044.32 $\mathrm{eV}$, respectively, while for the sample prepared by adding of $6 \mathrm{ml}$ of $\mathrm{NH}_{3}$ solution slightly shifted towards higher binding energy by $0.60 \mathrm{eV}$. This shift could be related to the changes in surface morphology and crystallinity as described in the preceding sections. In both cases, the spin orbit separation of $23.03 \mathrm{eV}$ between the doublets reveals the existence of $\mathrm{Zn}$ in the $\mathrm{Zn}^{2+}$ oxidation state and agrees well to the standard reference value of $\mathrm{ZnO}$ [31]. 

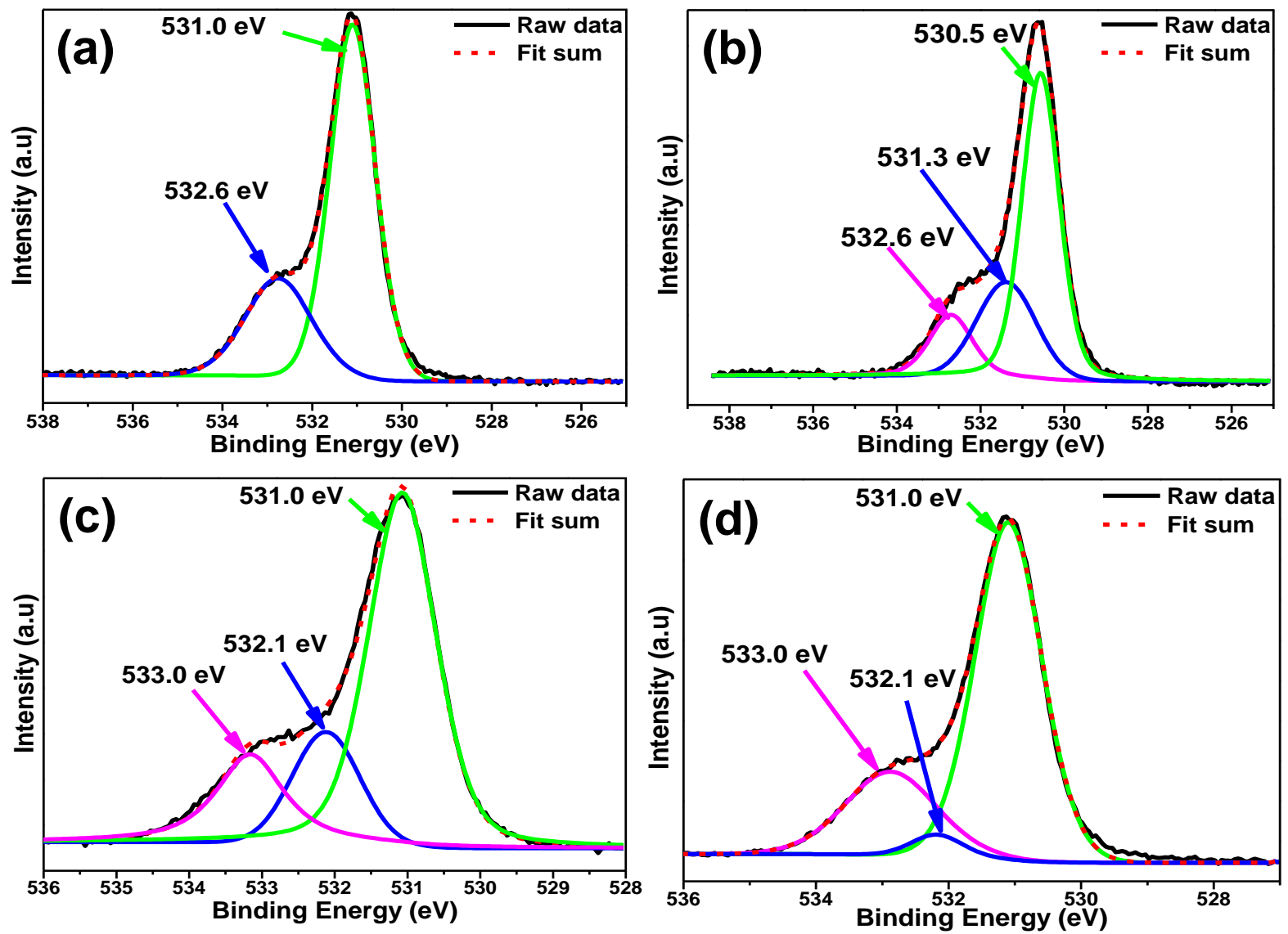

Fig. 7. High resolution XPS spectra of core-level photoelectron peaks of $\mathrm{O} 1 \mathrm{~s}$ of $\mathrm{ZnO}$ nanorods(a) reference sample, (b) $2 \mathrm{ml} \mathrm{NH}_{3}$, (c) $4 \mathrm{ml} \mathrm{NH}_{3}$ and (d) $6 \mathrm{ml} \mathrm{NH}_{3}$ solution.

Fig. 7a-d shows high resolution XPS scan of the O 1s core level photoelectron peak for the four samples. For the reference sample (Fig. 7 a), the $\mathrm{O} 1$ s peak was fitted with two Gaussian components: the lowest binding energy peak at $531.0 \mathrm{eV}$ is assigned to $\mathrm{O}^{2-}$ ions in the $\mathrm{Zn}-\mathrm{O}$ bonding of the hexagonal wurtzite structure of $\mathrm{ZnO}$. The second component located at a binding energy of $532.6 \mathrm{eV}$ is associated with $\mathrm{O}^{2-}$ that is present in the oxygen deficient regions within the $\mathrm{ZnO}$ matrix. On the contrary, $\mathrm{O} 1 \mathrm{~s}$ spectra of the sample prepared by adding $2 \mathrm{ml}$ of $\mathrm{NH}_{3}$ solution (Fig. $7 \mathrm{~b}$ ), $4 \mathrm{ml}$ (Fig.7 c) and $6 \mathrm{ml}$ (Fig. $7 \mathrm{~d}$ ) of $\mathrm{NH}_{3}$ solution was deconvoluted into three Gaussian components. The peak located at $530.5 \mathrm{eV}(2 \mathrm{ml} \mathrm{NH}$ solution) and $531.0 \mathrm{eV}$ for (4 $\mathrm{ml}$ and $6 \mathrm{ml}$ of $\mathrm{NH}_{3}$ solution) arise from $\mathrm{O}^{2-}$ in the $\mathrm{ZnO}$ bonding of the hexagonal wurtzite structure of $\mathrm{ZnO}$. The intermediate binding energy peak at 531.3 $\mathrm{eV}\left(2 \mathrm{ml} \mathrm{NH}_{3}\right.$ solution) and $532.1 \mathrm{eV}\left(4 \mathrm{ml}\right.$ and $6 \mathrm{ml}$ of $\mathrm{NH}_{3}$ solution $)$ is attributed to $\mathrm{O}^{2-}$ ions 
in the oxygen deficient within the $\mathrm{ZnO}$ matrix. The highest binding energy component at $532.6 \mathrm{eV}\left(2 \mathrm{ml} \mathrm{NH} 3\right.$ solution) and $533.0 \mathrm{eV}\left(4 \mathrm{ml}\right.$ and $6 \mathrm{ml}$ of $\mathrm{NH}_{3}$ solution) corresponds to the $\mathrm{OH}^{-}$groups adsorbed on the surface or arising during synthesis. The results are in good agreement with the previous report of $\mathrm{ZnO}$ nanostructures [32-36]. The change in the peak shapes and increased intensity of the highest binding energy components (Fig. $7 b-c)$, suggests that $\mathrm{NH}_{3}$ solution affects the surface composition of the nanorods. The $\mathrm{O}^{2-}$ ions in the oxygen deficient component peak intensity (intermediate binding energy peak) was diminishing while $\mathrm{OH}^{-}$(highest binding energy peak) peak intensity was increasing with $\mathrm{NH}_{3}$ indicating that $\mathrm{OH}^{-}$group was primarily induced during synthesis.

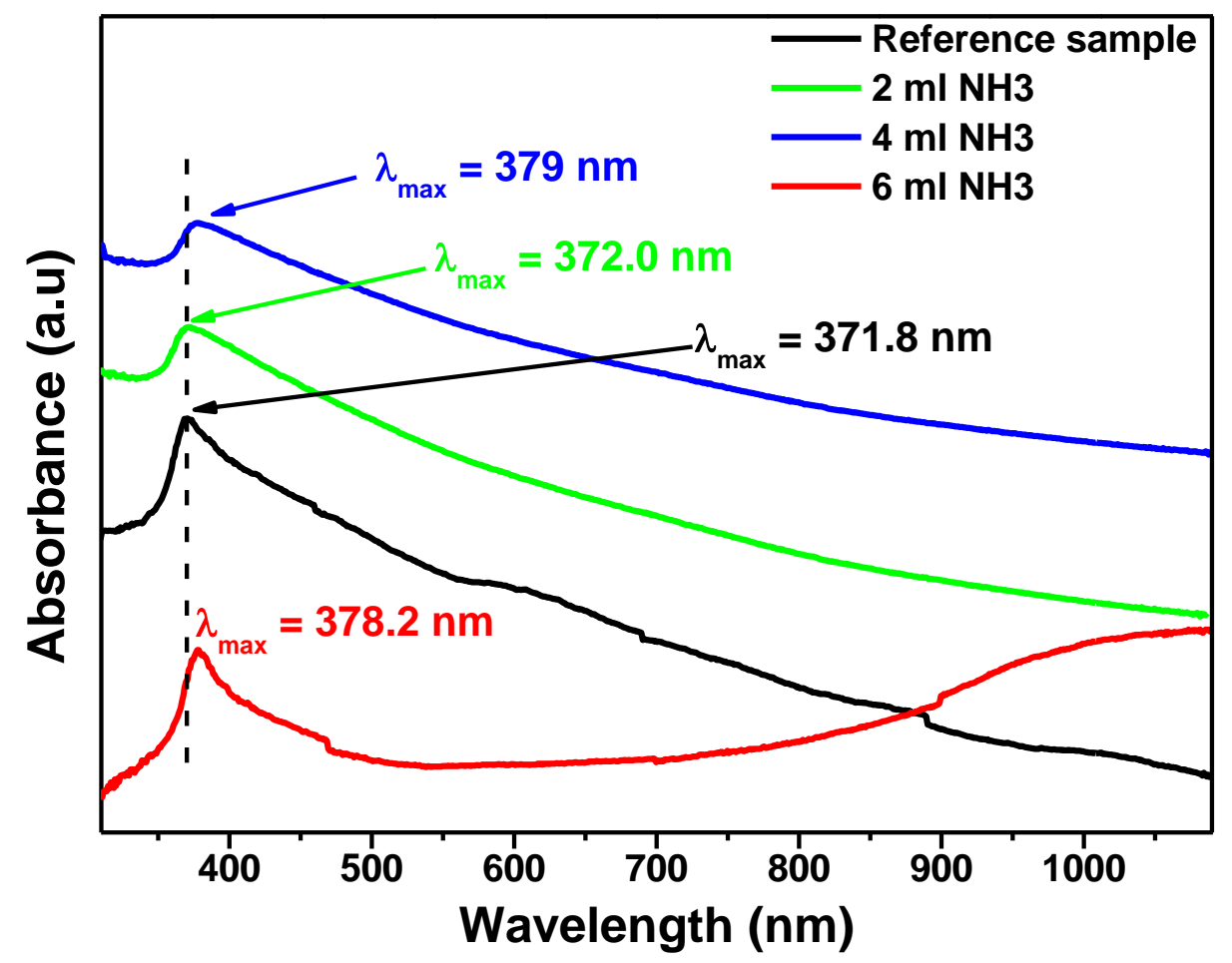

Fig. 8. Room-temperature absorption spectra of $\mathrm{ZnO}$ nanorods for reference sample, samples prepared by adding $2 \mathrm{ml}, 3 \mathrm{ml}$ and $6 \mathrm{ml}$ of $\mathrm{NH}_{3}$ solution.

Fig. 8 shows UV - vis absorption spectra measured at room temperature for the samples prepared without and with $\mathrm{NH}_{3}$ solution. All the samples showed absorption spectra with well-defined absorption peaks at wavelengths ranging from $371 \mathrm{~nm}$ to $379 \mathrm{~nm}$, revealing the characteristic absorption peak for $\mathrm{ZnO}$. The main absorption peaks for the reference sample, 
$2 \mathrm{ml}, 4 \mathrm{ml}$ and $6 \mathrm{ml} \mathrm{NH}$ of solution were $371.8 \mathrm{~nm}$ and $372.0 \mathrm{~nm}, 379 \mathrm{~nm}$ and 378.2, respectively and can be assigned to the intrinsic band gap absorption as previously reported [37]. It is worth noting the remarkable change in the absorption spectra of the sample prepared by adding $6 \mathrm{ml} \mathrm{NH}$ solution. The sample has increased absorption in the high wavelength region which could be attributed to the changes of the orientations of the nanorods due to increased concentration of $\mathrm{NH}_{3}$ solution in the growth nutrients.

Raman scattering results of $\mathrm{ZnO}$ nanorods prepared without adding ammonia (reference sample) and with 2, 4, and $6 \mathrm{ml}$ of ammonia are presented in Fig. 9. The observed peak at $333 \mathrm{~cm}^{-1}$ (labeled P1) for all samples indicates the $E_{2}($ high $)-E_{2}(l o w)$ mode due to multphonon process, it signifies that the nanorods were single crystals. The peak at $383 \mathrm{~cm}^{-1}$ (labeled P2) corresponds to the lattice vibration mode of quasi $A_{1}$ (TO) of $\mathrm{ZnO}$ crystal which was more pronounced in the reference sample and subsequently decreased with increase in ammonia concentrations. The sharp and most pronounced peak at $438 \mathrm{~cm}^{-1}$ (labeled P3) is attributed to $\mathrm{E}_{2}$ (high) mode and indicates high crystalline quality of the nanorods which further confirm the formation of wurtzite $\mathrm{ZnO}$. The Raman spectra intensities of $\mathrm{E}_{2}$ (high) mode decreased with increasing ammonia concentration suggesting that the crystallinity decreases with increased ammonia concentration which agrees well with XRD results. The presence of small peak at $585 \mathrm{~cm}^{-1}$ (labeled P4) can be assigned to $\mathrm{E}_{1}$ (LO) which was reported to be attributed to the lattice distortion [38]. In this study, intensity of this peak is weak, broad and increased with increase in ammonia concentration. 


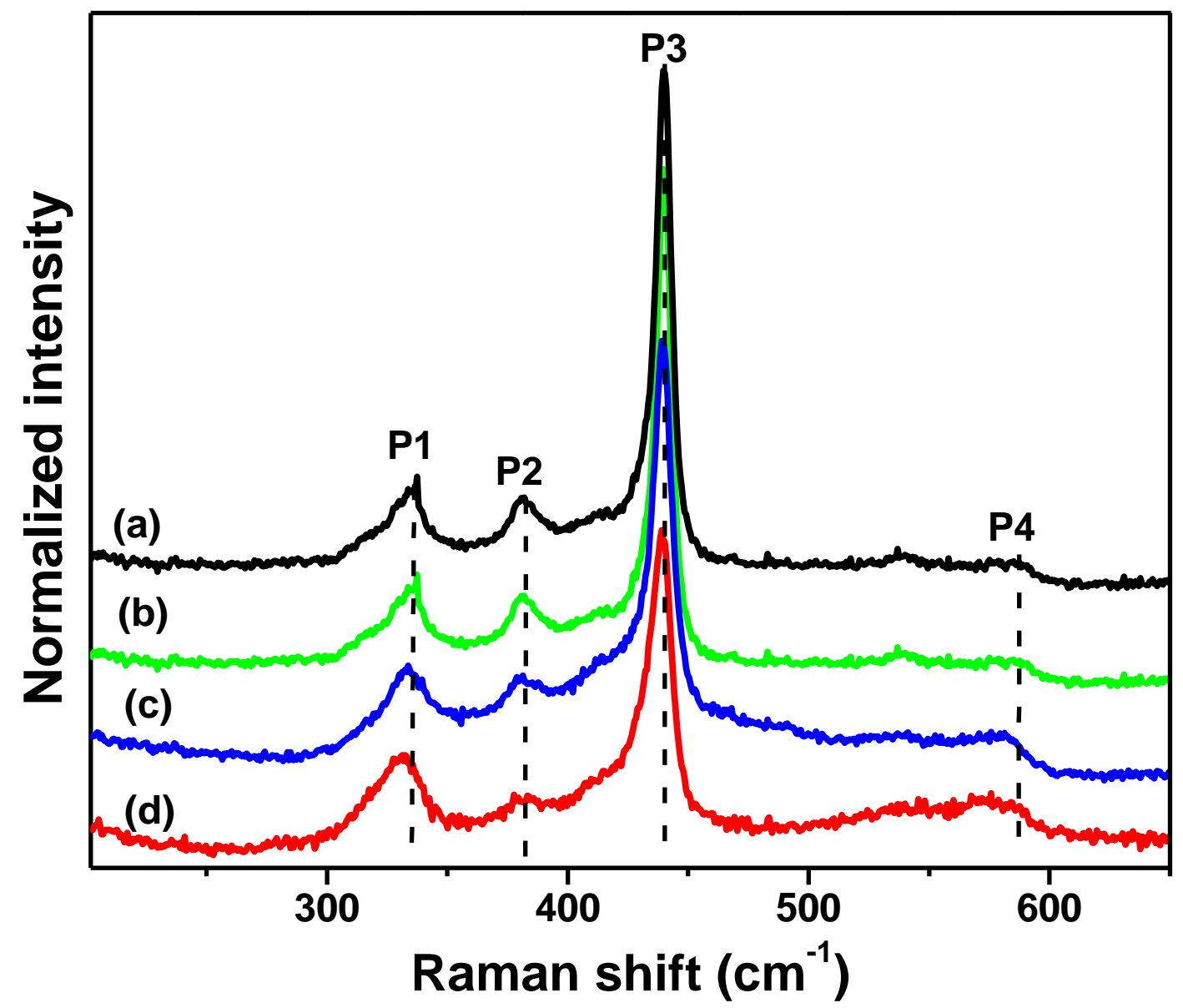

Fig. 9. Raman spectra for $\mathrm{ZnO}$ nanorods; (a) reference sample (without $\mathrm{NH}_{3}$ ), (b) $2 \mathrm{ml}$, (c) $4 \mathrm{ml}$ and (d) $6 \mathrm{ml}$ of $25 \% \mathrm{NH}_{3}$ solution.

We have observed slight peak shifts to lower frequencies with increasing ammonia concentration. The shifts can be attributed to spatial confinement, phonon localization and surface impurities as reported by Rana et al. [29]. The full width at half maximum (FWHM) of the $\mathrm{E}_{1}$ (high) labeled P3 (Fig. 9) was found to be $8.12 \mathrm{~cm}^{-1}$ for the reference sample, and increased upon successive addition of $\mathrm{NH}_{3}$ solution to $8.31 \mathrm{~cm}^{-1}, 9.67 \mathrm{~cm}^{-1}$ and $11.51 \mathrm{~cm}^{-1}$ for $2 \mathrm{ml}, 4 \mathrm{ml}$ and $6 \mathrm{ml}$, respectively. The decrease could be attributed to the decrease in crystalline quality of the samples as discussed in XRD results. The effective phonon energy $\left(E_{\mathrm{ph}}\right)$, which is a very important parameter for optical application is calculated using phonon mode position, FWHM $(\beta)$ and intensities $(I)$ of each corresponding peak using the equation below [39]. 


$$
E_{p h}=\frac{\sum_{i} E_{i} \beta_{i} I_{i}}{\sum_{i} \beta_{i} I_{i}}
$$

The obtained effective phonon energies are $349,394,405$ and $410 \mathrm{~cm}^{-1}$, for reference sample, 2, 4 and $6 \mathrm{ml}$ of ammonia, respectively. The calculated values increased with increase in $\mathrm{NH}_{3}$ concentration and thereafter will result in increased multiphonon losses. This observation may be due to the increased $\mathrm{OH}^{-}$concentration resulted from the decomposition of ammonia and thus changing the crystallographic planes of $\mathrm{ZnO}$ nanorods as discussed above.

Fig. 10 (a) shows linear $I-V$ characteristics of $\mathrm{Au} / \mathrm{ZnO} / \mathrm{ITO}$ and a picture of Schottky diode together with collection of nanorods forming individual Schottky contact (as shown in the insert). The nanorods underneath the Au metal could be considered as a collection of individual Schottky diodes connected in parallel. From Fig. 10 (a), we see that the device exhibits rectifying behavior indicating the formation of Schottky diode through Au contacts on $\mathrm{ZnO}$ nanorods. However, the rectification changes with the morphology resulted from the addition of ammonia. The sample prepared without addition of ammonia (reference sample) showed high rectification ratio at bias voltage of $\pm 1.5 \mathrm{~V}$ of 81.3 which decreased to $57.7,17$ and 10.4, for samples prepared by adding 2, 4 and $6 \mathrm{ml}$ of ammonia, respectively. This could be due to the fact that good contacts were obtained on top of the vertically grown nanorods with flat tops (having rectification ratio four times larger) than on the needle like structures. The more pronounced spaces between the nanorods as seen in FESEM images in Fig. 3 (c) and (d) resulted in a poor contacts between $\mathrm{Au}$ and $\mathrm{ZnO}$ nanostructures. From this result, we see that vertically aligned $\mathrm{ZnO}$ nanorods with flat tops display good properties for device performance. This agrees well with the study by Khan et al. [40] who reported different morphologies for example size, shape, density and orientation of nanostructures have large impact on the performance of the devises. Fig. 10 (b) shows semi-logarithmic $I-V$ 
characteristics of the Schottky diode clearly indicating rectifying behavior of the Schottky diode.
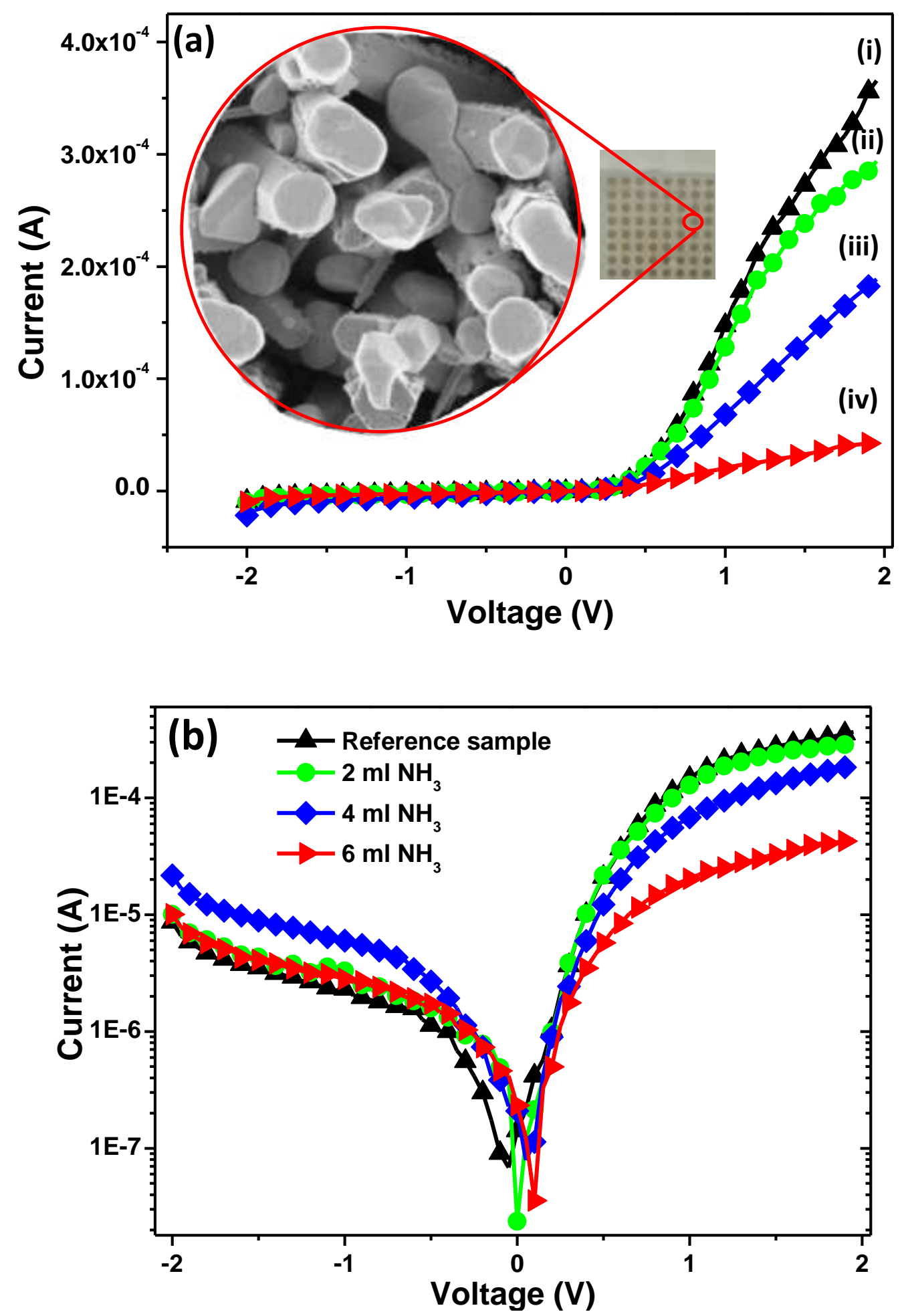

Fig. 10. (a) Linear $I-V$ characteristics of the Au/ZnO/ITO Schottky diode (i) reference sample, (ii) $2 \mathrm{ml}$ (iii) 4 $\mathrm{ml}$ and (iv) $6 \mathrm{ml}$ of $\mathrm{NH}_{3}$. The insert showing a picture of the Schottky diode and a collection of nanorods covered by a single Au contact. (b) its semi-logarithmic $I-V$ characteristics. 
The non-linear increase of the current in the forward bias can be well described by considering Thermionic emission theory [41].

$$
I=I_{0}\left[1-\exp \left(\frac{-q\left(V-I R_{s}\right)}{k_{B} T}\right)\right]
$$

where, $I_{0}$, the saturation current in the absence of external bias, given by:

$$
I_{0}=S A^{*} T^{2} \exp \left(\frac{-q \Phi_{B 0}}{\eta k_{B} T}\right)
$$

$k_{B}$ is the Boltzmann constant, $T$ is the absolute temperature, $S$ the diode contact area, $\mathrm{A}^{*}$ is the effective Richardson constant, $\Phi_{B 0}$ is the Schottky barrier height (energy barrier at the metal-semiconductor) and $\eta$, is the diode quality factor (ideality factor) which is an indicator of linearity in the $I-V$ characteristics. The $\eta$ were found to be $3.04,3.34,3.54$ and 3.02 for reference sample (without ammonia), 2, 4 and $6 \mathrm{ml}$ of ammonia, respectively. The obtained values of $\eta$ were found to be higher than 1 for ideal diode which could be due to a number of factors such as series resistance, surface and interface states and non-uniformity distribution of the interfacial charges and voltage drop across the M/S junction [42]. The $\Phi_{B 0}$ obtained from the fit were 0.75 for reference sample, 0.74 for $2 \mathrm{ml}, 0.72$ for $4 \mathrm{ml}$ and 0.70 for $6 \mathrm{ml}$ of ammonia. The results found to deviate from the theoretical one which was obtained from the difference between $\mathrm{Au}$ work function $(5.1 \mathrm{eV})$ and the electron affinity of $\mathrm{ZnO}(4.2 \mathrm{eV})$. Apart from the poor contacts between $\mathrm{Au} / \mathrm{ZnO}$, other factors like non-homogeneous barrier formation, Schottky effect (image-force- induced lowering) and dark regions that do not contribute to the current transport over the Schottky barrier could also probably caused this deviation $[43,44]$. These dark regions were reported to cause an error in the barrier height calculated from $I-V$ measurement [45]. Moreover, Schottky diodes based on $\mathrm{ZnO}$ nanostructures/thin films synthesized using chemical methods in air can induce interfacial dielectric layers that significantly alter $\Phi_{B 0}$ and strongly affect the current of the diode [46]. 


\section{Conclusion}

In summary, $\mathrm{ZnO}$ nanorods were successfully grown on annealed $\mathrm{ZnO}$ seeded substrate using low temperature CBD method and effects of adding ammonia in the growth solution was investigated. The FESEM images comfirms that ammonia affects the growth of the nanorods, where an increase in ammonia resulted in pronounced decrease in the diameter, density and changed orientation of the nanorods. The changes in the flat top hexagonal to tapered neddle like structures was associated with the increased $\mathrm{OH}^{-}$concentration. XRD results reveal a highly oriented wurtzite structure with intense, sharp, narrow diffraction peaks along (100) direction. All the synthesized $\mathrm{ZnO}$ nanorods had slightly higher lattice parameters as compared to the bulk $\mathrm{ZnO}$. XPS studies revealed the presence of $\mathrm{Zn}, \mathrm{O}$ and adsorbed $\mathrm{C}$ and the shift in the $\mathrm{Zn} 2 \mathrm{p}$ peak as well as changes in the shape of $\mathrm{O} 1 \mathrm{~s}$ spectra is consistent with the observed morphological and structural changes. Optical absorption and Raman studies showed characteristic absorption peak of $\mathrm{ZnO}$ and phonon dispersion peaks of the wurtzite $\mathrm{ZnO}$, respectively. The strong and sharp Raman peak at $438 \mathrm{~cm}^{-1}$ supports that the synthesized nanorods were of good crystalline quality with wurtzite structure. Electrical properties based on $I-V$ characteristics of $\mathrm{Au} / \mathrm{ZnO} / \mathrm{ITO}$ Schottky diode were measured. The diode exhibits rectifying behavior indicating the formation of Schottky diode through $\mathrm{Au}$ contacts on $\mathrm{ZnO}$ nanorods which changed with the addition of ammonia. The sample prepared without adding ammonia showed rectification ratio four times larger than the one prepared by adding $6 \mathrm{ml}$ of ammonia. The deviation of the ideality factor and barrier height could be due to the poor contacts between $\mathrm{Au} / \mathrm{ZnO}$, other factors also found to affect $\eta$ and $\Phi_{B 0}$ of the Schottky diode.

\section{Acknowledgements}

The work was financially supported by the University of Pretoria and National Research Foundation (NRF), South Africa, Grant No: 91550 and 94166. We also acknowledge the input of Onesmus Munyati of the University of Zambia. 


\section{Reference}

[1] K.H. Kim, K. Utashiro, Y. Abe, M. Kawamura, Growth of Zinc Oxide Nanorods Using Various Seed Layer Annealing Temperatures and Substrate Materials, Int. J. Electrochem. Sci. 9 (2014) 2080-2089.

[2] R. Mohamed, J. Rouhi, M.F. Malek, A.S. Ismail, a H. Salman, Sol Gel Synthesized Zinc Oxide Nanorods on Single And Co- doped ZnO Seed Layer Templates : Morphological , Optical and Electrical Properties, Int. J. Electrochem. Sci. 11 (2016) $2197-2204$.

[3] D. Gedamu, I. Paulowicz, S. Kaps, O. Lupan, S. Wille, G. Haidarschin, et al., Rapid fabrication technique for interpenetrated $\mathrm{ZnO}$ nanotetrapod networks for fast $\mathrm{UV}$ sensors, Adv. Mater. 26 (2014) 1541-1550. doi:10.1002/adma.201304363.

[4] D. Son, J. Im, H. Kim, N. Park, 11\% Efficient Perovskite Solar Cell Based on ZnO Nanorods: An Effective Charge Collection System, J. Phys. Chem. B. 118 (2014) $16567-16573$.

[5] D.H. Kim, J.H. Park, T. Il Lee, J.M. Myoung, Superhydrophobic Al-doped ZnO nanorods-based electrically conductive and self-cleanable antireflecting window layer for thin film solar cell, Sol. Energy Mater. Sol. Cells. 150 (2016) 65-70. doi:10.1016/j.solmat.2016.01.041.

[6] J. Lu, Z. Shi, Y. Wang, Y. Lin, Q. Zhu, Z. Tian, et al., Plasmon-enhanced Electrically Light-emitting from ZnO Nanorod Arrays/p-GaN Heterostructure Devices, Sci. Rep. 6 (2016) 25645. doi:10.1038/srep25645.

[7] H. Yadav, N. Sinha, S. Goel, B. Kumar, Eu-doped ZnO nanoparticles for dielectric, ferroelectric and piezoelectric applications, J. Alloys Compd. 689 (2016) 333-341. doi:10.1016/j.jallcom.2016.07.329.

[8] R. Saravanan, K. Santhi, N. Sivakumar, V. Narayanan, A. Stephen, Synthesis and 
characterization of $\mathrm{ZnO}$ and $\mathrm{Ni}$ doped $\mathrm{ZnO}$ nanorods by thermal decomposition method for spintronics application, Mater. Charact. 67 (2012) 10-16.

doi:10.1016/j.matchar.2012.02.015.

[9] S.J. Soenen, W.J. Parak, J. Rejman, B. Manshian, ( Intra ) Cellular Stability of Inorganic Nanoparticles : E ff ects on Cytotoxicity, Particle Functionality, and Biomedical Applications, Chem. Rev. 115 (2015) 2109-2135. doi:10.1021/cr400714j.

[10] M.T. Thein, S.Y. Pung, A. Aziz, M. Itoh, Stacked ZnO nanorods synthesized by solution precipitation method and their photocatalytic activity study, J. Sol-Gel Sci. Technol. 74 (2015) 260-271. doi:10.1007/s10971-015-3646-Z.

[11] S. Duo, Y. Li, H. Zhang, T. Liu, K. Wu, Z. Li, A facile salicylic acid assisted hydrothermal synthesis of different flower-like $\mathrm{ZnO}$ hierarchical architectures with optical and concentration-dependent photocatalytic properties, Mater. Charact. 114 (2016) 185-196. doi:10.1016/j.matchar.2016.02.021.

[12] N. Preda, M. Enculescu, C. Florica, A. Costas, A. Evanghelidis, E. Matei, et al., Morphology-controlled synthesis of $\mathrm{ZnO}$ structures by a simple wet chemical method, Dig. J. Nanomater. Biostructures. 8 (2013) 1591-1600.

[13] L. Yan, A. Uddin, H. Wang, ZnO Tetrapods : Synthesis and Applications in Solar Cells Review Article, Nanomater. Nanotechnol. (2015). doi:10.5772/60939.

[14] L. Zhang, Y. Yin, Large-scale synthesis of flower-like $\mathrm{ZnO}$ nanorods via a wetchemical route and the defect-enhanced ethanol-sensing properties, Sensors Actuators, B Chem. 183 (2013) 110-116. doi:10.1016/j.snb.2013.03.104.

[15] R. Shabannia, Vertically aligned $\mathrm{ZnO}$ nanorods on porous silicon substrates: Effect of growth time, Prog. Nat. Sci. Mater. Int. 25 (2015) 95-100. doi:10.1016/j.pnsc.2015.03.002.

[16] Y. Kumar, A.K. Rana, P. Bhojane, M. Pusty, V. Bagwe, Controlling of ZnO 
nanostructures by solute concentration and its effect on growth, structural and optical properties, Mater. Res. Express. 2 (2015) 0. doi:10.1088/2053-1591/0/0/000000.

[17] V. Strano, R.G. Urso, M. Scuderi, K.O. Iwu, F. Simone, E. Ciliberto, et al., Double Role of HMTA in ZnO Nanorods Grown by Chemical Bath Deposition, J. Phys. Chem. C. 118 (2014) 28189-28195. doi:10.1021/jp507496a.

[18] S. Xu, Z.L. Wang, One-dimensional ZnO nanostructures: Solution growth and functional properties, Nano Res. 4 (2011). doi:10.1007/s12274-011-0160-7.

[19] M.A. Abbasi, Z.H. Ibupoto, M. Hussain, G. Pozina, J. Lu, L. Hultman, et al., Decoration of $\mathrm{ZnO}$ nanorods with coral reefs like $\mathrm{NiO}$ nanostructures by the hydrothermal growth method and their luminescence study, Materials. 7 (2014) 430440. doi:10.3390/ma7010430.

[20] M.A. Desai, S.D. Sartale, Facile soft solution route to engineer hierarchical morphologies of ZnO nanostructures, Cryst. Growth Des. 15 (2015) 4813-4820. doi:10.1021/acs.cgd.5b00561.

[21] J.J. Richardson, F.F. Lange, 2009, Cryst. Growth Des. 9 (2009) 2570-2575.

[22] B.S. Mwankemwa, M.J. Legodi, M. Mlambo, J.M. Nel, M. Diale, Structural, Morphological, Optical and Electrical properties of Schottky diodes based on CBD deposited ZnO:Cu Nanorods, Superlattices Microstruct. 107 (2017) 163-171. doi:10.1016/j.spmi.2017.04.018.

[23] L. Chen, Y. Yin, C. Chen, The influence of Polythyleneimine and Ammonium on the Growth of ZnO Nanowires by Hydrothermal Method, J. Phys. 115 (2011) 2091320919. doi:10.1021/jp2056199.

[24] Z. Khusaimi, M.H. Mamat, N. Abdullah, M. Mohammad Rusop, ZnO Nanostructures - Nanorods and Flower-Like on Si/Au Substrates by Solution-Immersion Method in Different pH of Precursor, Adv. Mater. Res. 667 (2013) 86-92. 
doi:10.4028/www.scientific.net/AMR.667.86.

[25] A. Aravind, M.K. Jayaraj, M. Kumar, R. Chandra, Optical and magnetic properties of copper doped ZnO nanorods prepared by hydrothermal method, J. Mater. Sci. Mater. Electron. (2012) 106-112. doi:10.1007/s10854-012-0911-6.

[26] S. Azad, E. Sadeghi, R. Parvizi, A. Mazaheri, Fast response relative humidity cladmodified multimode optical fiber sensor with hydrothermally dimension controlled ZnO nanorods, Mater. Sci. Semicond. Process. 66 (2017) 200-206. doi:10.1016/j.mssp.2017.04.024.

[27] T.H. Kwon, K. Kim, S.H. Park, A. Annamalai, M.J. Lee, Effect of seed particle size and ammonia concentration on the growth of $\mathrm{ZnO}$ nanowire arrays and their photoconversion efficiency, Int. J. Nanotechnol. 10 (2013) 681-691. doi:10.1504/ijnt.2013.054210.

[28] I.W. Okpashi, V.E. Obi Bonaventure, C. Uchechukwu C Okoro, Synthesis and Characterization of Zinc Oxide ( $\mathrm{ZnO})$ Nanowire, J. Nanomed. Nanotechnol. 06 (2015). doi:10.4172/2157-7439.1000321.

[29] A.K. Rana, Y. Kumar, N. Saxena, R. Das, S. Sen, P.M. Shirage, Studies on the control of $\mathrm{ZnO}$ nanostructures by wet chemical method and plausible mechanism, AIP Adv. 5 (2015). doi:10.1063/1.4930598.

[30] M.A. Gaikwad, M.P. Suryawanshi, S.S. Nikam, C.H. Bhosale, J.H. Kim, A. V. Moholkar, Influence of $\mathrm{Zn}$ concentration and dye adsorption time on the photovoltaic performance of M-SILAR deposited ZnO-based dye sensitized solar cells, J. Photochem. Photobiol. A Chem. 329 (2016) 246-254. doi:10.1016/j.jphotochem.2016.07.006.

[31] R. Yousefi, Effects of Sn atoms on formation of $\mathrm{ZnO}$ nanorings, CrystEngComm. 17 (2015) 2698-2704. doi:10.1039/C5CE00316D. 
[32] K. Shingange, Z.P. Tshabalala, O.M. Ntwaeaborwa, D.E. Motaung, G.H. Mhlongo, Highly selective NH3 gas sensor based on Au loaded $\mathrm{ZnO}$ nanostructures prepared using microwave-assisted method, J. Colloid Interface Sci. 479 (2016) 127-138. doi:10.1016/j.jcis.2016.06.046.

[33] A. Saáedi, R. Yousefi, F. Jamali-Sheini, A.K. Zak, M. Cheraghizade, M.R. Mahmoudian, et al., XPS studies and photocurrent applications of alkali-metals-doped $\mathrm{ZnO}$ nanoparticles under visible illumination conditions, Phys. E Low-Dimensional Syst. Nanostructures. 79 (2016) 113-118. doi:10.1016/j.physe.2015.12.002.

[34] J.W. Zhang, G. He, T.S. Li, M. Liu, X.S. Chen, Y.M. Liu, et al., Modulation of microstructure and optical properties of Mo-doped $\mathrm{ZnO}$ thin films by substrate temperature, Mater. Res. Bull. 65 (2015) 7-13. doi:10.1016/j.materresbull.2015.01.004.

[35] T.G.G. Maffeis, M.W. Penny, A. Castaing, O.J. Guy, S.P. Wilks, XPS investigation of vacuum annealed vertically aligned ultralong ZnO nanowires, Surf. Sci. 606 (2012) 99-103. doi:10.1016/j.susc.2011.09.007.

[36] S.B. Ambade, R.B. Ambade, S.H. Eom, M.-J. Baek, S.S. Bagde, R.S. Mane, et al., Cofunctionalized organic/inorganic hybrid $\mathrm{ZnO}$ nanorods as electron transporting layers for inverted organic solar cells, Nanoscale. 8 (2016) 5024-5036. doi:10.1039/C5NR08849F.

[37] A. Khorsand Zak, W.H.A. Majid, H.Z. Wang, R. Yousefi, A. Moradi Golsheikh, Z.F. Ren, Sonochemical synthesis of hierarchical $\mathrm{ZnO}$ nanostructures, Ultrason. Sonochem. 20 (2013) 395-400. doi:10.1016/j.ultsonch.2012.07.001.

[38] K. Samanta, P. Bhattacharya, R.S. Katiyar, Raman scattering studies of p-type Sbdoped ZnO thin films, J. Appl. Phys. 108 (2010). doi:10.1063/1.3516493.

[39] R. Das, A. Kumar, Y. Kumar, S. Sen, P.M. Shirage, Effect of growth temperature on 
the optical properties of $\mathrm{ZnO}$ nanostructures grown by simple hydrothermal method, RSC Adv. 5 (2015) 60365-60372. doi:10.1039/C5RA07135F.

[40] A. Khan, M. Hussain, M.A. Abbasi, Z.H. Ibupoto, O. Nur, M. Willander, Study of transport properties of copper/zinc-oxide-nanorods-based Schottky diode fabricated on textile fabric, Semicond. Sci. Technol. 28 (2013) 125006. doi:10.1088/0268$1242 / 28 / 12 / 125006$

[41] S.M. Sze, Physics of Semiconductor Devices, Third edit, Wiley, New York, 1979.

[42] N.S. Singh, L. Kumar, A. Kumar, S. Vaisakh, S.D. Singh, K. Sisodiya, et al., Fabrication of zinc oxide/ polyaniline (ZnO/PANI) heterojunction and its characterisation at room temperature, Mater. Sci. Semicond. Process. 60 (2017) 29-33. doi:10.1016/j.mssp.2016.12.021.

[43] A. Kathalingam, Senthilkumar, S. Valanarasu, J.-K. Rhee, Shape-dependent electrical property of solution synthesized ZnO nanorods, Semicond. Sci. Technol. 27 (2012) 105006. doi:10.1088/0268-1242/27/10/105006.

[44] G.N. Narayanan, R. Sankar Ganesh, A. Karthigeyan, Effect of annealing temperature on structural, optical and electrical properties of hydrothermal assisted Zinc Oxide Nanorods, Thin Solid Films. 598 (2015) 39-45. doi:10.1016/j.tsf.2015.11.071.

[45] D.A. Neamen, Semiconductor physics and devices, Third Eddi, Mac Graw Hill, 2003.

[46] L.J. Brillson, Y. Lu, ZnO Schottky barriers and Ohmic contacts, J. Appl. Phys. 109 (2011). doi:10.1063/1.3581173. 